\title{
Inequity and Cultural Differences in Out-of-School Science Education: The Case of the Arab Minority in Israel
}

\author{
Tali Tal \\ Corresponding author, \\ Faculty of Education in Science and Technology, Technion - Israel Institute \\ of Technology, \\ Haifa, 3200o, Israel \\ rtal@technion.ac.il
}

Received: 12 August 2020 | Revised: 4 November 2020 | Accepted: 18 November 2020

\begin{abstract}
This paper examines the gap between Jewish and Arab students in Israel in the context of learning in informal environments. I attempted to understand whether the difference is a matter of inequity in terms of resource allocation and opportunities provided to the schools. I present the socio-historical-political context and the current situation, based on formal documents. To gain an insiders' views, I interviewed five Arab science educators and an Arab superintendent. These conversations highlighted the cultural aspect of the gap and a cultural change toward integrating more learning opportunities in out-of-school environments. Using Gutiérrez and Rogoff (2003), rather than taking a deficit view, repertoires of practice is suggested to understand differences. Several implications relevant to other places where different cultural groups live and where educational and social practices affect the ways people use out-of-school time and resources are offered.
\end{abstract}

\section{Keywords}

informal learning environments - awareness - culture - resources - Jewish - Arab outdoor learning 
[The Arab] teachers explicitly expressed their expectation for "enrichment and enjoyment." They did not expect the program to be connected to the school curriculum. They viewed the program as an opportunity to "promote the school," as a "leverage" and as a trigger to develop care for the environment. They repeated their expectation that the students enjoy the activity. The principal was the only person who pointed out connections to the curriculum. He was the one who suggested highlighting the topic of water consumption and saving in school while the program focuses on the nearby Tabor Creek. However, the principal was present only in the planning and the wrap-up meetings, and eventually the teachers did not request making such connections.

MORAG, TAL, \& KEREN-ROTEM, 2O13, p. 438

The above quote demonstrates the tension in Arab schools in Israel with respect to the goals and practice of field trips: merely fun or a learning opportunity? This paper looks at the differences between Israeli-Arab schools and Jewish schools in the ways they view field trips to informal learning environments and asks if the differences are due to discrimination and inequity or to cultural differences between the Jewish and Arab societies in Israel.

\subsection{Context}

My own research over the last twenty years has focused mainly on science and environmental education in informal settings, such as natural history and science museums, nature parks, botanical gardens, and zoos, as places where students can engage with science in ways that are different from the sequencebased and curriculum constraints. The literature on informal learning environments shows that close interaction with objects, living organisms, and real phenomena, when done with fellow students, friends, family, and/or other involved or significant adults, contributes a great deal to the development of cultural habits, interest, motivation, care for the environment, and many social skills (e.g., Falk \& Dierking, 200o; NRC, 2009; Tal, 2012; Tishler, Ben-Zvi Assaraf, \& Fried, 2020). However, there is evidence that underserved communities and minorities do not have the same access to informal science education institutions and that these communities and minorities feel excluded, even when they visit such institutions (Dawson, 2014, 2017; Feinstein \& Meshoulam, 2014). In Israel, there are significant socio-economic gaps between the Jewish and the Arab populations. Unlike the formal education system in which the same curricula are used in the two segments of Israeli society, in the informal arena 
there is a major difference. This is something I have observed in the past and have continued to notice in the present. Evidence shows that Israeli-Jewish children have many more opportunities to visit and to learn in informal settings (Dallasheh \& Tal, 2019) such as museums and also that fewer Arab students take part in excursions to natural environments that involve hands-on activities and hiking. In general, fewer after-school science programs operate in Arab towns, fewer field trips are offered by Arab schools, and fewer Arab families spend their leisure time in museums and in nature parks. My observations are supported by Arab educators and by official publications of the Israeli Ministry of Education and the Knesset (the Israeli parliament) (Abu Safi, 2016; Asfur, 2020; The Knesset Research and Information Center, 2016).

\section{Theoretical Underpinning}

Less frequent use of informal learning environments by minorities is not unique to Israel. Dawson (2017) points to data from 2012 showing that, although between one fifth and one half of people in China, Japan, South Korea, India, Malaysia, the United States, the European Union, and Brazil visited zoos, aquaria, and science museums, participation in out-of-school science learning is far from being equal and is marked by advantage, not least by the social axes of age, social class, and ethnicity. Dawson shows how social justice theory can support the establishment of after-school and adult clubs for minorities, where their knowledge and practices can be respected and valued. So far, this general call makes much sense in the Israeli context. However, Dawson's expectation that, through better engagement with equitable out-of-school learning environments, "normative social structures about who can do science remain problematic and appear to limit strong forms of social justice and inclusive practice" (p. 544), is somewhat less relevant. Despite Arab students and Arab youth having less access to out-of-school science activities, both Arab schools and families push their students to excel in science to increase social mobility. In my institution, which is a first-tier institution, for example, the percentage of Arab undergraduate students is equal to their percentage in the population of the country. Nevertheless, Dawson's (2014) work shows that minority groups visiting museums and other informal science education institutions feel ethnically excluded, and they believe that museums are "for children rather than adults." These insights support some of my own observations as well as statements made by my Arab colleagues, which are provided the Conversations with Israeli-Arab Researchers and Educators section. Dawson elaborates on language barriers, which are less significant in the context of this paper. 
First, all the major informal science education (ISE) institutions in Israel have bilingual signs and websites. Second, organized activities such as school visits are enacted in Arabic for Arab students. In her study, Dawson addresses noncognitive learning outcomes reported by minority participants, who enjoyed the social experience no less. In this regard, our own work (Bamberger \& Tal, 2008; Mintz \& Tal, 2014) has shown the potential of learning in informal environments to enhance non-cognitive outcomes, which ranged from educative interactions with peers to greater motivation to developing interest. Yet we see that ISE institutions do not become places Arab families would consider visiting during school vacation or on the weekend.

In their seminal paper "Cultural Ways of Learning: Individual Traits or Repertoires of Practice" Gutiérrez and Rogoff (2003) offer the "cultural styles" approach to deal with cultural differences rather than the deficit view of the minority in comparison with the dominant culture. A repertoire of practice is developed through an individual's prolonged participation in a cultural community. This approach offers "an alternative by characterizing cultural ways of different groups in terms that are respectful, attempting to describe them without making value judgments that suggest value hierarchies in cultural practices" (p. 19). Gutiérrez and Rogoff advocate looking for cultural regularities rather than looking for individual practices. They suggest that we focus our examination of differences on cultural processes in which individuals engage with other people in dynamic cultural communities, some of which involve ethnic or racial group membership. By cultural community they refer to "groups of people with some traditions and understandings in common, extending across several generations, with varied roles and practices and continual change among participants as well as transformation in the community's practices" (p. 21). Moreover, the idea of repertoires of practice can actually frame the design of the learning environment and the educational activity, which can be referred to as "design for equity" (DiGiacomo \& Gutiérrez, 2017). Although it is important to note that while linguistic competencies are central to bi- or multilingual education systems and that this is not the case in Israel, where the Arab minority has its autonomy and chooses to teach in Arabic, other aspects such as culturally relevant mediation and addressing student histories, culture, ways of knowing, and social structures are important for ISE institutes.

In light of the above, the difference between the ways and the extent to which the Arab and the Jewish populations enjoy informal science education environments seems at first like a clear equity issue with respect to resources and access. However, in line with Gutiérrez and Rogoff (2003), I intend to 
discuss relevant cultural-historical-political issues that contribute no less to this apparent difference. The questions I wish to address in this paper are:

1. In what ways does the pattern of inequity reflect the general socioeconomic gap between the two societies, given that Arab schools, and the Arab population in general, are disadvantaged in terms of higher poverty levels and fewer resources allocated by the government to the Arab education system?

2. In what ways do cultural and historical factors affect access to ISE?

To address these questions, I discuss prior research on Jewish and Arab students in Israel learning in informal environments, present the culturalhistorical-political context and a few relevant documents and reports, and report on informal interviews - which I prefer to call "conversations" - with a few Israeli-Arab science educators, with a member of the Knesset (the Israeli parliament), and with an official from the Ministry of Education. As I do not speak Arabic fluently, and as all the participants are excellent Hebrew speakers the conversations were held in Hebrew and the quotes are translated to English. In these conversations, I asked only one leading question: Can you please address learning in informal environments in Arab society? The transcripts were sent to the participants, who were asked to confirm or edit their responses. Additional information was received from the directors of three major science and natural history museums about trends, visits, and the activities of the Arab student population.

\section{Prior Research}

Concern about the gap in learning in informal environments has led me to carry out a number of projects with my graduate students that address this gap in one way or another. In our projects, we attempt to work with educators and organizations to increase participation of Arab students in out-of-school learning opportunities. As I have already acknowledged, I strongly believe in the power of informal experiences with science and in a variety of forms of engagement with science. About a decade ago, we carried out two extended collaborative environmental projects involving Jewish and Arab high school students (Alkaher \& Tal, 2014; Tal \& Alkaher, 2010). In these projects, student groups together investigated local conflicts over land use between Arab villages and nature parks, and they initiated activist efforts to protect nature while addressing local needs. 
Organizations engaged in these endeavors included Jewish and Arab schools, local authorities, NGOs, the Israel Nature and Parks Authority, and local resident groups. We found that students enjoyed learning together about genuine conservation vs. development controversies that involved historical and political aspects, but that the Arab students, who had fewer outdoor learning experiences, enjoyed the encounters more. At the end of the projects, students had better knowledge of each other and of each other's environmental views and concerns. In another project, we studied extended environmental education projects offered separately to Jewish and Arab elementary school groups in nature parks. Each group visited the nature park a few times and took part in hands-on nature conservation activities. We found that although the Arab teachers had much local knowledge and strong place attachment, the outdoor educator did not embrace their knowledge and did not use their experience (Morag et al., 2013).

To challenge Arab pre-service science teachers' hesitation about outdoor learning and to help them teach outdoors, we carried out an action-research project in an ecological garden that served us as a "pedagogical field lab" in which the student-teachers acted as facilitators in a safe environment. They co-designed the activities, enacted them in the ecogarden, with support of the researchers, and discussed their experience in the larger group (Tal \& Morag, 2009). Masar School - an Arab school from the city of Nazareth - is a unique K-12 progressive school with a clear mission "Masar's strategic orientation for social change is to 'act locally in order to impact globally' in the field of education, so that we can contribute to the development of both the Palestinian community and the society as a whole." Transformative education is its main goal, stating that:

Through its school initiative, Masar is endeavoring to produce systematic change in Israel at the grassroots, community and governmental levels. At the grassroots level, Masar is contributing to the development of empowered, expressive and creative Palestinian children, parents, teachers and school administrators (Masar website, u.d.)

We followed an environmental education program of the school that included major out-of-school experiential learning designed and enacted by a teacher who studied the design and the impact of the program. We found evidence for meaningful learning about the environment, student care for their heritage, and pride in their community (Danial \& Tal, 2014). We continued our efforts to work in the Arab community with an initiative to bring high school biology students to a medical simulation-based environment at a science center that 
offered a unique experience involving learning about the human body and its functions through sophisticated human-like simulators (Dallasheh \& Tal, 2019, Tal \& Dallasheh, 2021). In order to bring these schools to the science center for three consecutive visits, almost all their expenses had to be waived. The students showed growing interest in biology and medicine and better conceptual understanding of the circulatory system and of the idea of a healthy lifestyle.

We believe in the power of lifelong learning in informal environments, and in all these efforts we have tried to promote learning in informal environments and to understand the obstacles that Arab schools and teachers face when incorporating more learning in informal settings.

\section{The Israeli Socio-Political Context}

The Israeli education system is segregated into four main groups (referred to as "sectors"): Jewish secular, Jewish orthodox, Jewish ultra-orthodox, and Arab. Altogether, the Arab population makes up about 21\% of Israeli citizens. The Israeli-Arab population consists of a Muslim majority (85\%) and small Christian and Druze minorities. Jewish and Arab citizens commonly live in different towns and attend different schools. The teaching language is Arabic in the Arab schools and Hebrew in the Jewish schools. All students study English from fourth grade, and, in addition, Arab students also study Hebrew, which is the official language of Israel. Arabic is an elective course in Jewish schools, but most Jewish Israelis do not speak Arabic. Israeli authorities refer to Arab citizens as "Israeli Arabs," hence the terms Arab schools, Arab towns, Arab students, and so forth. Many Arab citizens, especially the younger and more educated ones, prefer the term "Palestinian citizens of Israel." Using the word "Palestinian" emphasizes their national roots and their relationship with the Palestinian people. Using the word "citizen" distinguishes them from the Palestinians who live in the occupied territories, who do not hold Israeli passports and who struggle for independence. I respect this terminology, but for brevity, and to avoid acronyms, I will use the term "Israeli Arabs" hereafter.

In Israeli society, there is a well-known discrepancy between the opportunities of Jewish and Arab students with respect to enrichment programs. Apart from a few high-achieving and excellent Arab schools, there are significant differences in the students' achievements in national and international standardized tests such as PISA and TIMSs. The Myres-JDC-Brookdale Report (2018) shows consistent improvement in education levels among Arab citizens, but the achievement gap is still significant, with few Arabs graduating from high school with a matriculation diploma that enables acceptance to higher 
education institutions. PISA outcomes of Arab students are significantly lower than that of Jewish students.

The Israeli Central Bureau of Statistics reports show consistent socioeconomic differences between Jewish and Arab communities, with most Arab communities ranked in the lowest economic deciles (СBS, 2016 yearly report). On the other hand, the Israeli government allocates more resources to underserved communities than to average and above average ones. In principle, a student from the lowest decile of income (first decile) will be budgeted 6o\% more than a student from the 1oth decile. Yet students from affluent communities will be better funded through their municipalities, above and beyond government funding, and will be better supported by their families, especially through additional enrichment programs in school and through after-school activities provided by science centers, arts programs, sports, and so forth.

The field-nation-society (FNS) curriculum and Israel Studies encompass cultural and heritage education and outdoor education. Abu Safi (2016), the former Ministry of Education's Arab superintendent of FNs, argues that Arab schools in Israel face conflicting expectations: sustaining and embracing the traditional values of a society that has not internalized modern democratic values while at the same time being part of a modern Arab society that expects schools to provide students with tools and competencies to integrate into the modern, advanced, Western, and competitive Israeli society. Abu Safi stresses that FNS and Israel Studies aim at connecting the students to themselves, to nature, and to various circles of culture and heritage in the diverse Israeli society. As such, he claims that FNS is expected to strengthen the students' Arab identity as well as their Israeli identity. He highlights the success of outdoor learning in FNS and concludes that the program can contribute in a balanced and sensitive way to the transition from a conservative to a modern and integrated society.

A somewhat different picture is presented in a report on access to museums by the Knesset Research and Information Center (RIC). The report points to a substantial difference in the distribution of museums across the country, with many more museums located in the big cities and fewer in the rural regions in which the majority of the Arab population and the more disadvantaged Jewish population live. Out of 151 museums, only $25 \%$ are in the Northern District, and only $11(7 \%)$ in the Southern District where most Arabs live. Except for recent local initiatives around art and heritage, there are almost no museums 
located in Arab towns, although there are museums in the large, mixed cities. A survey of the Israel Central Bureau of Statistics quoted in the report showed that $40.5 \%$ of Jewish respondents had visited a museum in the previous twelve months, compared with $12.5 \%$ of Arab respondents. Moreover, most of the museums in the rural areas are small, which limits the number of student visitors they can serve and the number of exhibits and activities they can offer. Unlike the big museums in the main cities, some of the small museums are also not accessible to the Arab population because they do not offer relevant activities, Arabic-speaking staff, or signs written in Arabic. The report stresses that even if these small museums are located close to major Arab population centers, due to the aforementioned reasons, they hardly serve this population.

The KIR K report on access to museums supports the literature (e.g., Dawson, 2014; Feinstein \& Meshoulam, 2014) that emphasizes that the main purpose for which science museums and science centers were established was to overcome the state of inequality in science education by making them accessible to the broadest and most diverse public. However, evidence shows that these learning environments mostly serve visitors who are already succeeding in school and in society. In addition, it seems that, despite growing research in the field, few researchers have examined how these informal learning environments are supposed to challenge the gap between the present situation and the desired situation. We acknowledge the gap identified in the United States and United Kingdom by Feinstein and Meshoulam (2014) and Dawson (2014, 2017), and in Israel by Sedawi, Ben-Zvi Assaraf, and Cwikel (2014).

In my own work, especially when equity issues are involved, I look at several layers of context: the history of an educational program's target audience, the political context, the history of education in the community, and any relevant events in the recent past or present that might affect learning. For example, in the above-mentioned environmental education program in an Arab community that was in conflict with a government nature-conservation agency, we needed to address the different views of the local Arab population toward nature conservation and exploitation, especially with respect to wild herb harvest in protected areas. In an attempt to better communicate with the local community, the nature protection agency assigned an Arab facilitator to work with the school. However, although the environmental educator who represented the environmental agency was Arab, and despite the students' enjoyment and their high self-reported outcomes, the program's success was limited (Morag et al., 2013). Representing the environmental agency, the facilitator maintained his power and gave almost no opportunity to discuss other views about nature that might be brought by the students and the school teachers. Although his mother tongue was Arabic and he spoke Arabic to the students, he 
spoke a "foreign" language to the locals with respect to nature conservation. He hardly referred to the students' life experiences or the teachers' personal and the community's histories, and attempted to deliver an "out-of-context message" about nature conservation to his audience. Another issue in this regard was the complex background of all the adults involved in the program. The teachers were from a Muslim village, the facilitator was from another Muslim town, one researcher was a Christian Arab who lived in a city and had a cosmopolitan way of life, and two other researchers were Hebrew-speaking Jews. In a way, this diversity represented a number of contexts for the educational and environmental discourse that were not fully addressed (Tal, 2012).

As in other areas of education in Israel, field trips to natural environments have a historical-political context (Tal, 2016). A field trip to a natural environment is viewed as a way of learning about the geography, history, and natural history of the area, as well as about the cultural heritage. Donaldson and Donaldson (1958) had already defined outdoor education as learning about the outdoors (natural history, archeology, and geography) in the outdoors and for the outdoors. But in the Israeli context, it encompassed a transition from the European urban life of the Jewish diaspora, where Jews were not allowed to own and cultivate land, to living in harmony with nature and becoming attached to the Land of Israel.

The field trip became not only a central means of teaching about the environment, but also a means of developing new sets of values that were influenced, on the one hand, by the idea of learning through direct experience with the environment (natural pedagogy), and, on the other hand, by nationalistZionist thought that aimed at connecting the Jews to their homeland. Apparently, these two motives still shape the current policy of the Israeli Ministry of Education regarding field trips. However, the two sources of influence existed long before the State of Israel was established in 1948, and before any formal policy was formulated. Questions then arise: What is the place of Arab schools in this set of values? To what extent was the Arab population influenced by progressive educational ideas brought to Israel by immigrant pioneers in the early 190os, and what was the impact of the Jewish-Zionist view of field trips on the Arab population? In other words, in the Arab population's view, do "Israeli field trips" represent another colonialization effort? This can highlight and explain why hiking - by individuals or in groups - is 
uncommon among Israeli Arabs, although a significant portion of Arab society was rural until the end of the 2oth century, with a strong farming and grazing background. Asfur (2020), the current superintendent of the FNS curriculum at the Ministry of Education, which guides, coordinates and oversees outdoor education, has written that Arab society has gone through a significant change in the last three decades, in both family and school contexts, in its approach to the outdoors. While in the past, excursions were mainly to visit attraction tourist sites such as amusement parks, tourist cruises or kayaking, and much of the time during these events was dedicated to shopping and eating, recently many schools visit national parks and heritage sites and more emphasis is given to "Loving the Homeland" (an Israeli idiom) place-based education and education for environmental awareness. In the family context, outings are still focused on swimming, picnics, and playing in woods and parks.

According to Asfur, the implementation of the FNS curriculum, which has a strong outdoor learning component, in both Arab schools and in Jewish schools, has initiated the change. Asfur argues that the Ministry of Education has invested a lot to advance the culture of outdoor education in Arab society. Abu Safi (2016), who focused on culture and tradition in Arab society, argues that obeying religious and old family norms is still very prevalent in this society. The school, he argues, which is a constitutive institution, is challenged by two conflicting expectations: internalizing traditional conservative values while also encouraging the younger generation to integrate into the Western, modern, and economically successful Israeli society. Similar to Asfur, Abu Safi believes that the FNS curriculum, which is based mainly on outdoor learning, addresses these expectations by strengthening the Arab students' connectedness to their homeland and to their cultural values, while also building their integrated Israeli identity.

To further explore my questions, I had several individual and group conversations with Arab science educators and researchers who represented different groups within the Arabic-speaking population of the country and one superintendent of FNS. The following topics were discussed in the conversations: learning in informal environments opportunities for students, community and school culture, the educational staff's awareness of outdoor and informal education, and resources. The five participants in the conversations are presented in Table 1. 
TABLE 1 The participants in the conversations

\begin{tabular}{|c|c|c|}
\hline & Education & Current position \\
\hline Abeer & $\mathrm{PhD}$, science education & $\begin{array}{l}\text { Interim Dean of Science of an } \\
\text { Arab Teachers' College }\end{array}$ \\
\hline Sameer & PhD, science education & Science teacher \\
\hline Lilian & $\begin{array}{l}\text { PhD candidate, science } \\
\text { education }\end{array}$ & $\begin{array}{l}\text { Science and biology teacher and a } \\
\text { PhD student }\end{array}$ \\
\hline Doris & MSc, science education & $\begin{array}{l}\text { Informal educator, environmental } \\
\text { education }\end{array}$ \\
\hline Sondos Saleh / KM & $\begin{array}{l}\text { MSc student, science } \\
\text { education }\end{array}$ & $\begin{array}{l}\text { Knesset (Israel Parliament) } \\
\text { Member and former biology } \\
\text { teacher }\end{array}$ \\
\hline Omar & MA, Israel Studies & $\begin{array}{l}\text { Ministry of Education } \\
\text { Superintendent of FNS }\end{array}$ \\
\hline
\end{tabular}

In this section, I present the main themes of the conversations. I use the term "conversations" to emphasize the unstructured, think-aloud, and thoughtsharing nature of the dialogue. In no way were the conversations formal interviews. After completing writing the draft of this paper, I asked the first five to read it and correct me if I had misinterpreted their arguments. I held a telephone conversation with the sixth.

\subsection{Culture and Awareness of Education in Informal Environments}

Surprisingly, although they all mentioned the insufficient resources in Arab schools, this was only a secondary or tertiary factor. The two main themes they all referred to were culture and awareness of education in informal environments: This awareness was referred to as part of the culture. Unsurprisingly, Knesset Member (KM) Saleh expressed more politicized views, critiquing both government policy and the Arab school administration.

Abeer, the interim Dean and incoming Dean of the Science Department of an Arab teachers' college, who throughout held various leadership positions in the college said:

The biggest problem is awareness rather than resources. Even with no resources, you can take students out to their neighborhood, the school yard, or send them to explore their own yard. We have, for example, an 
olive press near school, but no teacher takes the kids to visit and learn about it.

To explain this lack of attention to what the environment offers, Abeer referred to a course I teach on outdoor education and explained:

There is no such course on teaching science in informal settings in my college, so how can you expect teachers to realize it's important?

Sameer, a science teacher holding a $\mathrm{PhD}$ in science education, addresses the same theme.

Teachers are less aware of the importance and don't know how to guide learning in such environments. They act passively and trust only the [informal] facilitators. I don't know if this is due to [a lack of] professional development. It's the school's attitude. If the pedagogical staff acknowledge its importance, it would definitely happen. Right now, it's just another outing, not an educative field trip.

Sameer refers to a past attempt to persuade Madatech, the biggest science center in the country, to open an extension in an Arab town.

It failed because they [local policy makers] thought only about how to get the exhibits rather than thinking and working on other important aspects such as training the staff, according the recommendations of the science center.

Sameer addresses the issue referring to leading administrators as well:

Even the superintendents of Arab schools aren't aware enough of the importance of learning in informal environments. Consequently, its place in the curriculum is limited. With proper awareness, the financial issue can be resolved.

Lilian, a PhD candidate and a high school teacher who taught environmental sciences and research in healthcare systems courses, elaborated and directly connected the culture of Arab society with awareness.

The picture is complex. It begins in the family and in childhood with opportunities. Going to the outdoors is perceived as related to leisure 
time rather than to education and learning. It is always connected to food [picnics] and barbeques. Otherwise it's not considered. It will always involve hanging out in a shopping mall as well.

She describes a well-planned field trip of her school which ended with the students hanging out in an amusement park that was the highlight of the field trip. More specifically, she addresses tradition and lifestyle:

Going out to natural environments is related to dirt. Unlike going to a jamboree, for example. One aspect of modernization in the Arab society was shifting away from farming to urbanized communities and distancing from the land, so activity in nature, or getting muddy, seems inappropriate. A child coming back home dirty is a "disaster to his/her Mom."

Lilian refers to her own experience of outdoor leisure activities in Germany where she studied for her PhD - as a "personal shock" to see how common outdoor activities are. She agrees with Sameer that awareness is key and says that if administrators and policy makers could be convinced, outdoor activities would become part of the curriculum. She specifically described her own school, which serves students from low socio-economic backgrounds.

I carry out field trips in my two courses. In environmental sciences, a major mandatory unit is a class outdoor investigation [making $20 \%$ of the matriculation exam], so it helps [to enforce]. There's no other option. We have to go out. However, I have to make sure we end in a shopping mall or with a barbeque, otherwise the students would not cooperate.

Lilian added that the effort in planning and carrying out the field trip in this unit falls solely to the teacher, which makes it extremely demanding.

Then she addresses financial obstacles, but with respect to habits and culture, saying that despite the students' poverty and parents refusing to pay for enrichment programs in school, the families will spend a lot on food, meat, and soft drinks on those picnics. She refers to priorities that are culture related and adds that poor families spend large amounts of money on brand items and on having a good time but not on education.

Doris, an environmental educator employed by a county in northern Israel and who in the past worked for the biggest environmental NGO as an educational coordinator for Arab communities, emphasizes the role of school principals: 
Many parents do not understand the importance of a museum, a hike or of being outside in nature. You can integrate outdoor education if the principal wants to. These principals [in the Arab community] also have political power in their towns, and they understand the relationships with civic organizations and the government.

She refers to missed opportunities due to the passive attitude common to many principals.

The Ministry of Education published this Call for Proposals for fourth grade outdoor education programs. Principals had only to register to secure their school's facilitators [a resource provided by the state], but we had to beg them to register, and eventually they missed it. On the other hand, there were [other] principals who immediately took the opportunity and registered, in addition to adopting hiking clubs and encouraging museum visits.

\subsection{Current and Alternative Practices}

Lilian argued that the proper time to begin outdoor education is in kindergarten and then children grow up into it. In the big Arab city where she lived and worked, both Christian and Muslim children from higher economic status commonly enroll in private schools, mainly church schools. She herself has taught in a semi-private school funded by a not-for-profit organization, and she addressed the difference.

The difference is huge. Masar [where she previously taught] is a small $\mathrm{K}-12$ school with only one class per cohort. The communication I was able to develop with students and parents there is impossible for me now. The community [there] was very supportive and the message delivered by the principal on quality of field trips was clear to all. In my current school, even a good field trip coordinator ended taking the students to an amusement park rather than visiting a museum or hiking.

Lilian added that having the students in a confined place prevents unsafe encounters, decreases the chance of possible injuries, and allows the teachers to sit in one place and observe their students. By that she means that the teachers need to change too. When they did manage to go out with the students, the field trips were in the style of "walk and talk," with formal lectures from non-educators. 
The students had little chance to engage in their physical environment and experiment and were bored most of the time. They preferred that I myself teach them the concepts rather than just listening to others speaking. In such settings, I am expected (by, for example, the hospital staff or the nature parks we visit) to keep students quiet and ensure their good behavior. And when I tried to engage, it was seen as an "interruption" and taking time from the lecturer.

\subsection{Differences within Arab Society}

Doris, the environmental educator, contributed her insights from the point of view of organizations working to promote outdoor education in Arab communities. Doris addressed some differences between the Druze community to which she belongs and the rest of the Arab-speaking society, arguing that, in general, the picture is better in the Druze education system due to a higher awareness of the importance of informal science-education environments. The scope of this paper does not allow the author to get into specific social and ethnic differences, but politically the Druze see themselves as an integral part of Israeli society and they also serve in the Israeli army. This clearly distinguishes them from the rest of Arab society, and their political and social identity is different than that of the mainly Muslim Arab citizens. Doris also pointed to differences between urban and rural communities and emphasized the complexity of integrating informal environments.

Doris agreed with Lilian about the different out-of-school learning culture in the Arab population, but said that like in other areas, individuals do make a change. To support her claim, she gave an example of a teacher who, with no support of the school administration, has led the school's parent association to support her in conducting a whole program of learning in informal settings in her school. She concluded that despite a general lack of enthusiasm, individuals in the Arab school system make observable changes.

\subsection{Initial Change}

Abeer referred to the start of a "top-down" change and gave two examples. One example was a new program for B.Ed in science education that she was involved with under the initiative of the Council for Higher Education. She said that the first draft was rejected by the council and was sent for revision with a demand to identify the future graduates of the 21st century, with an emphasis on informal learning opportunities. Eventually, the revision included a detailed plan to integrate out-of-school learning. The second example was the initiative of the Council for Conservation of Heritage Sites in Israel to develop a heritage-based 
program for outdoor learning in the Arab college. The program would consist of four field trips and nearly 60 hours of learning. Abeer pointed to a long and slow transition process of understanding what education in informal settings is and then slowly adopting it.

Similarly, Lilian finished her conversation by saying that she now noticed the start of a "back to the land" trend that might affect outdoor learning, but until it does, the obstacles of culture, awareness, and resources impede proper out-of-school learning.

\subsection{Inequity: Lack of Resources}

An important conversation was held with Sondos Saleh, a KM representing the United Arab Parties who is a science teacher and who, until she was recently elected, had taught in a private Arab school. KM Saleh, who identifies herself as a "feminist Palestinian Citizen of Israel," pointed to the mixture of poverty, lack of economic equality, and insufficient awareness of innovative pedagogies as the complex reason for the differences. She argued that unequal government investment in Arab students prevents them from enjoying all the opportunities Jewish students have. She specifically talked about the lack of parks and cultural institutions in Arab towns. On the other hand, she pointed to insufficient student motivation that has a negative impact on Arab students. She made a link between this low motivation and the job-assignment system of Arab teachers by the Arab school system administration.

Novice Arab teachers who graduated with state-of-the-art pedagogical knowledge don't get to teach. [She then talks about her own experience.] Although I am a science teacher and a graduate of the most prestigious program, I could not teach [in public schools], so I taught in a private one ... There is an assignment key which is based on seniority and political power in the municipality, or a powerful family. The knowledge and motivation of the [current, older] teachers is low, and the younger and more educated teachers cannot penetrate.

Sondos addresses the cultural aspects referred to by all the other participants, but also integrates a few powerful variables.

It's the family culture. You go out to eat and leisure. Very few families are interested in walking or seeing natural phenomena. It [lack of outdoor education] is related to the infrastructure and opportunities, to who the teachers are and to the families. The student is the victim of all these. 
She refers back to the cultural transition that Lilian referred to, saying that:

Going to nature is to bring food, to shepherd the goats and sheep and cultivate the land [not to hike]. In the mixed cities, there is more outdoor activity for sports and spiritual ventilation. Learning is still the last priority.

After reading the above section, KM Saleh asked to add that:

Eventually, it reflects the complexity of the socio-political status of Arab society. As an indigenous minority which is in conflict with the state, with high rates of poverty, unemployment and discriminatory budgeting, the priorities of the Arab family are different to be able to survive everyday life. This affects schooling in general, and out-of-school learning in particular. The absence of cultural institutions and places to hang out makes the field trip an opportunity to spend good time with friends rather than being a learning environment. The Ministry of Education's preference of high-stake assessments focused on achievements and numbers encourages merely motivation to get high grades rather than develop deeper gains.

During the conversations, I remembered a paper I read many years ago. The author, who was a researcher of Jewish immigrants from Middle Eastern countries, critically asked, "How [were] Ashkenazi [Jews] taught to love nature and hiking?" referring to the cultural gaps between European (Ashkenazi) Jews and those who immigrated from Middle Eastern countries in the 1950s. The paper begins with a vignette of a young outdoor educator complaining about the lack of interest and enjoyment of nature of the children from second-generation Middle Eastern immigrant families. The outdoor educator argued that "these guys just don't want such field trips, they hate nature and even harm it, they prefer walking in the city and enjoying shopping." When the author asked him the simple question, "How come you love nature and they don't?" he got confused, first saying that it was an unrelated question, but after further probing, he said that there was a 50-year gap between him and the Middle Eastern students. In his paper, Stahl (1993) argues that originally, Jews living in the diaspora had a negative attitude toward nature and hiking, but that European Jews in the early 190os were strongly inspired by a new spirit of learning in 
and learning from nature, which was influenced by philosophers in Europe. His claim regarding immigrant Jews from Middle Eastern countries who need more time and enculturation can be expanded to the Arab population of the country. This line of thought focuses on the culture of the community and how it affects attitudes to learning in out-of-school environments.

Other publications (Avissar, 2011; Dror, 2011; Gertel, 2010; Tal, 2016) have also referred to the importance of outdoor education in Israel, in the creation, establishment, and maintenance of the Israeli-Jewish identity rooted in Biblical stories and places, which then developed throughout the history of the Jews in the Land of Israel. Traditionally, this reinforced national identity has excluded the Arab minority from this communal ethos. Unlike the strong and consistent enculturation of the Jewish students, no such messages were communicated to Arab students or developed in Arab schools. While Jewish children were taken outdoors to appreciate the wonderful, modern, and successful agriculture that has been Israel's main export and source of revenue in the past decades, Arab children learned to hide their families' traditional farming traditions, because they were underdeveloped and because being a farmer or a shepherd meant being left behind. As Lilian indicated, being modern means abandoning farming and learning modern professions such as medicine, law, and engineering. Indeed, the professional shift has greatly contributed to the higher social mobility and improved socio-economic status of the Arab population. At the same time, however, it has contributed to a growing distance between Arab citizens and nature.

\section{9}

\section{A Dynamic Transition}

Only recently, due to increasing environmental awareness in general, has there been a growing movement that challenges this distance between Arab citizens and nature and that draws on traditional practices as the inspiration for smaller scale, local, and more environmentally friendly agriculture.

A pioneer institution in Arab society is the Towns Association for Environment Quality (TAEQ) which has integrated six municipalities and provided guidance, support, and management across broad environmental and educational fields. In its mission "planting the seeds of change," TAEQ declares:

TAEQ was founded in 1993 by scientists and educators wishing to raise awareness of environmental issues within Israel's Arab society. It was the first environmental initiative to emerge from the Arab-Israeli sector. Situated in the Galilee, TAEQ has become a place where Arab and 
Jewish Israelis come together in joint stewardship of their common environment.

TAEQ, u.d.

By supporting local and environmentally friendly agriculture and proper water treatment facilities, offering teachers professional development, and inspiring a return to traditional building, the organization is slowly but steadily leading the local population of nearly 100,000 in a new approach to the environment and to outdoor learning.

In museums as well, the presence of Arab students is constantly growing. Information received from the three major science and natural history museums in the three big cities - Jerusalem, Tel Aviv, and Haifa - shows that one third to one half of the visiting students to the museums are Arab. The Ministry of Education's program Central Experiences in Science and Technology supports student visits to science and natural history museums according to a key that favors underserved schools. Every class engaged in the program has a preparatory meeting with the science teacher, an initial lesson in school given by the museum staff, a guided visit to the museum, and a wrap-up activity in school, again enacted by the museum staff. Of all schools that visit museums, the proportion of Arab schools is higher than the proportion of Arabs in the total population (21\%). The natural history museum, for example, runs an activity that brings together Jewish and Arab students in Grades 4 and 5 . The combined groups have eight visits in Grade 4 and four visits in Grade 5. The lessons and the worksheets are offered in both languages, and all the museums employ Arabic-speaking educators. In addition, the education coordinator of one of the science centers indicated that, besides the organized activities, a growing number of principals and teachers organize transportation and chaperones to visit the science center during the five open days each year. On the other hand, she acknowledged that fewer Arab families visit the science centers on a regular basis when admission is charged and when no special activities are offered. This is despite the fact that all signs are in Arabic as well. This education director also points to a cultural barrier and to the need to change priorities with regard to leisure time in Arab society.

\section{Should We Look at the Field Trips to Outdoor Environments at All?}

As indicated earlier, Stahl (1993) years ago expressed his critique of the deficit views of outdoor educators of the Jewish youth with Middle Eastern roots they worked with. This is the place to highlight an ongoing debate over the 
activity called the "Yearly Excursion" in the Israeli educational system at large. As already indicated, the roots of outdoor education in Israel stem from two areas. The first is educational philosophy and the belief of learning in nature and learning from nature, the freedom of exploration, hands-on learning, and making abstract concepts visible and accessible. The second is the revival of the Jewish nation in Israel, the need to tie the population of immigrants to the archeology and history of the Land of Israel and work on their local Israeli identity (Tal, 2016). The Yearly Excursion was usually a 3- to 4-day experience that involved substantial hiking in remote locations - often in the desert that was physically, emotionally, and socially challenging for many students. "Knowledge of the land" was the term used to describe the need of such experiences, and "knowing the land through the legs" became an idiom used by educators to explain the nature and value of the hikes. In the last three decades, there have been continuous calls to revisit the goals and practices of the Yearly Excursion. Ben David (1988), for example, describes the cultural conflicts student feel when an outdoor educator asks them hold a wild animal's dry stool in their palms and take it apart to learn about the animal's nutrition and then tells them to burn their own toilet paper and stool to avoid littering. For some, holding any stool is a shocking and repulsive experience. Milner (2000) asks whether hiking with big groups of students on the edge of a cliff is necessary as a "didactic strategy" to teach students about the geology of the desert, or is it an unnecessary life-threatening risk? According to Milner, the Jewish students themselves believe that this physical challenge is necessary for social bonding. This type of social bonding was cultivated in Israeli youth movements and school excursions in line with annealing the youth to prepare for army service. Milner sees in these experiences traces, or even mirroring, of the late European Wandervogel ("wandering bird") movement that was a popular movement of German youth groups from 1896 to 1933. These groups protested against industrialization by going hiking in the country and by communing with nature in the woods.

These questions about the merits of the pinnacle of outdoor education in Israel make me ask: Why should anyone expect the Arab education system in Israel to align with practices that are strongly influenced by the Zionist movement and its educational values when these values are criticized in the Jewish education system as well? However, not all field trips aim to galvanize the youth, and a day's field trip to investigate water quality in the nearby creek, an ecological investigation in the woods or in a rocky habitat, or a treasure hunt in the city following its historical landmarks are not in any way symbols of colonialism, or an adoption of "Israeli values." These are all known practices worldwide that have been extensively studied in the last decade. As all 
the Arabic colleagues who discussed learning in informal environments have stressed, this is more a difference of attitude and culture than a difference of accessibility.

I add here a balanced picture given by Omar, the current Arab FNs Ministry of Education superintendent. He agreed with the picture presented by my science educator colleagues, but claimed that it was only true until more than a decade ago, when a new framework for outdoor education in Arab society was adopted. Due to the economic gap between Jewish and Arab citizens, he argued, there was no room for, and no attention paid to, what is perceived to be additional and far beyond basic education needs. Therefore, in the past, the only trip was the Yearly Excursion, which was an opportunity to enjoy attractions rather than to provide an educative experience. Nowadays, he argues, 95\% of Arab schools submit a field trip plan for approval, and this is nothing like what was seen a decade ago. This direction is good, he said, although there is still a way to go in comparison to Jewish society. He believes that the weakest link is still the teacher, and he referred to the older teachers who would not adapt to the changes. The new activity in the Arab schools - expressed through the appointment of field trip coordinators in the schools, field trip committees, and teachers' professional development - is exciting, he said, yet one can expect that 15 years will be needed to close the gap in learning in informal environments. This official's words correspond with what KM Saleh said about the assignment system that is delaying the integration of younger and more qualified teachers. His words echo what Stahl (1993) described as a cultural and time gap between European and Middle Eastern Jews' attitudes toward outdoor education.

\section{Discussion}

Gutiérrez and Rogoff (2003) argue that to understand differences such as the ones described in this paper, development of cultural activities should be considered. They also argue that it is necessary to examine the nature and forms of cultural artifacts and tools used; the social relations, rules, and division of labor; and the historical development of individuals and communities. They suggest that researchers should focus on "understanding the development of individuals and communities, make first guesses about patterns, and seek confirmation or disconfirmation to extend what is known" (p. 23). Accordingly, I asked my Israeli-Arab colleagues to describe the picture as they saw it and let me know whether they considered my understanding correct or incorrect. 
The idea of cultural practices is very helpful for understanding the differences between Jewish and Arab schools' use of informal learning environments. This theoretical framework enables the examination of different practices, in this case the field trip, in light of the different histories and cultures of Jewish and Arab students, teachers, and schools.

Dawson (2018, p. 772) opens her paper with a quote from an interview with a man named Abdou, from a Sierra Leonean group visiting a museum in the United Kingdom. Abdou states explicitly that a museum visit would be something he would never consider, saying that the museum is something you cannot connect with. It is for "other people that it matters to." Dawson then raises the questions about whose values, knowledge, and culture such science communication practices reproduce. Moreover, she criticizes science communication practices that exclude low-income and minority people from the dominant culture. The information gathered for this paper from many individuals - Arab science educators, museum directors, an Arab official from the Ministry of Education, and an Arab director of education in a leading NGO - point to a significant difference with regard to Israel. Yes, the Arabs in Israel are discriminated against in many ways. The schools are under-resourced, and the majority of them are located in what is termed in Israel as the "geographical and social periphery." In the case of Israel, the common perception is that the core of the country corresponds with the metropolitan areas of Tel Aviv, Haifa, and (to an extent) Jerusalem, and that the remainder of the national space represents the periphery or a set of peripheral regions where most Arabs, but also Jews, live. The term "social periphery" refers to underprivileged populations, regardless of where they live. In general, the peripheral regions offer fewer opportunities to access museums and after-school programs, not only in science but also in arts and sports. On the other hand, Arab society is highly motivated to improve social mobility and academic excellence. Many schools integrate demanding programs, focus on high-stakes tests and encourage their graduates to apply to prestigious programs in higher education institutions. A higher percentage of Arab students enroll in elective science programs in high school compared with Jewish students. In $2016,13 \%$ of Jewish students majored in biology while $34 \%$ of Arab students did, $5.6 \%$ of Jewish and $15.5 \%$ of Arab students majored in chemistry, and $8.6 \%$ of Jewish and $7.8 \%$ of Arab students majored in physics (RIC, 2018). At the Technion, a leading science and engineering university in Haifa, $20 \%$ of the graduates are Israeli Arabs, reflecting their proportion in the Israeli population. In that sense, relying on social justice literature and on accessibility to science and science institutions is problematic in the Israeli case. It is clear that a gap exists between how Jewish and Arab schools and 
individuals see the contribution of informal science environments. However, it is evident as well that all institutions are working toward narrowing this gap. Yet, in line with DiGiacomo and Gutiérrez (2017), the idea of repertoires of practice refers as well to the design of exhibits, to the learning activity, and to the facilitation offered by the ISE institution.

This means that more attention should be given not only to bringing more Arab students and offering more activities in Arabic, but also to the proper design of the activity. Such sensitivity could make more families and individuals feel comfortable in museums as well. It is apparent that socio-economic factors alone cannot explain the difference in employing informal learning environments in Israel, and that cultural differences play a major role as well, as was apparent in the conversations I held. Issues such as the approach to dirt, hiking, and the outdoors, whether for leisure or as a learning opportunity, and the lower number of Arab-family visits to museums, even in the city where the museum is, all play a role in how informal learning environments and activities in those environments are perceived. Stahl (1993) concludes his paper by arguing that the time needed to change the views and values of Ashkenazi (European) Jews was much longer than the time it took Middle Eastern Jews to change their perceptions of the natural environment and field trips. His positive view about this cultural change is supported, in the context of this paper, by information gathered from documents and individuals who were willing to help me clarify this complex issue. This leaves a lot of space for optimism about narrowing the resource and cultural gap between Jews and Arabs in Israel with respect to using informal learning environments to teach about science and about the environment and heritage of the peoples living in Israel. Many Arab children now get the opportunity to visit the major museums, schools are changing with respect to how field trips should look, and younger teachers are enthusiastic about using informal learning environments. I believe that more Arab families will visit the museums and tour nature reserves and heritage sites in the future. Time is a major factor in this ongoing process of adapting cultural practices.

In many countries, student field trips to informal learning environments are generally overlooked. Inequity, which is related to resources that enable this important activity, can be found worldwide, and has been substantially addressed internationally in publications such as the United Nations 
Sustainable Development Goals (UN, 2015) that address, for example, quality education, reduced poverty, and responsible consumption, and the Organization of Economic Co-operation and Development's (OECD) recognition of non-formal and informal learning stressing that "non-formal and informal learning is an important means for making the lifelong learning for all' agenda a reality for all and, subsequently, for reshaping learning to better match the needs of the 21st century knowledge economies and open societies," (OECD, nd) which will help promote equity.

Cultural differences related to views about schooling and its goals could create obstacles to using the many opportunities that out-of-school activities provide, such as exploring a city park, investigating museum exhibits, interviewing elderly people sitting in the park, or conducting an inquiry project in a creek or on a mountain slope. To challenge these social and cultural differences, educators and researchers should maintain dialogues about the culture of schooling, community cultures, mutual expectations and specific barriers. Only through continuous dialogue will we be able to tailor the suit that fits each cultural group, and through that suit, to further develop the discourse on informal learning environments and the ways in which they can be utilized to maximize the variety of learning outcomes they enable.

\section{Abbreviations}

$\begin{array}{ll}\text { FNS } & \text { field-nation-society } \\ \text { ISE } & \text { Informal Science Education } \\ \text { KM } & \text { Knesset Member } \\ \text { NGO } & \text { Non-Governmental Organization } \\ \text { PISA } & \text { Programme for International Student Assessment } \\ \text { RIC } & \text { Research and Information Center } \\ \text { TAEQ } & \text { Towns Association for Environment Quality } \\ \text { TIMSS } & \text { Trends in International Mathematics and Science Study }\end{array}$

\section{Acknowledgements}

I wish to express my gratitude to all the interviewees for this paper who generously contributed their time and happily discussed with me and in the group the challenges and affordances of outdoor education in Arab society in Israel. 


\section{Ethical Considerations}

Data collected in this study was done so with permission of the participants. All the interviewees for this paper preferred using their real names and gave their consent to publish the text they approved.

\section{About the Author}

Tali Tal is a professor of science and environmental education at the Technion, Israel Institute of Technology. Currently, she is the Dean of the Faculty of Education in Science and Technology and the Immediate Past President of NARST, a global organization for improving science education through research.

\section{References}

Abu Safi, N. (2016). Education, society, culture and FNS and Israel Studies in the Arab Society. Conference on the Field Trip as an educational and value means (pp. 73-83). Tel-Aviv University.

Alkaher, I., \& Tal, T. (2014). The impact of socio-environmental projects of Jewish and Bedouin youth in Israel on students' local knowledge and views of each other. International Journal of Science Education, 36, 355-381.

Asfur, O. (2020). The field trip in the Arab Society, in a changing reality. The second conference on educative field trips, Beit-Berl College.

Avissar, O. (2011). Good to hike for our land: The development of the field trip myth in the national Zionist education. In: G. Cohen \& Eli Shaish (Eds.). The field trips as an educational and value tool (pp. 59-87). Jerusalem: The Ministry of Education (in Hebrew).

Bamberger, Y., \& Tal, T. (2008). Multiple outcomes of class visits to natural history museums: The students' view. Journal of Science Education and Technology, 17(3), 274-284.

Ben David, O. (1988). Society and nature in the Society for Protection of Nature in Israel. MA Thesis, Tel Aviv University (in Hebrew).

Central Bureau of Statistics (2016). Statistical Abstract of Israel, 2016.

Dallasheh, S., \& Tal, T. (2019, March-April). The Impacts of School Visits to a Medical Simulation-Based Informal Learning Environment. The Annual NARsT Conference, Baltimore, MD. 
Danial, L., \& Tal, T. (2014, June-July). Towards education for sustainability in an Arab school in Israel - a case study. European Researchers in Didactics of Biology (ЕRIDOB) bi-annual conference, Haifa, Israel.

Dawson, E. (2014). "Not Designed for Us": How Science Museums and Science Centers Socially Exclude Low-Income, Minority Ethnic Groups. Science Education, 98(6), 981-1008.

Dawson, E. (2017). Social justice and out-of-school science learning: Exploring equity in science television, science clubs and maker spaces. Science Education, 101(4), 539-547.

Dawson, E. (2018). Reimagining publics and (non) participation: Exploring exclusion from science communication through the experiences of low-income, minority ethnic groups. Public Understanding of Science, 27(7), 772-786.

DiGiacomo, D. K., \& Gutiérrez, K. D. (2017). Seven chilis: making visible the complexities in leveraging cultural repertories of practice in a designed teaching and learning environment. Pedagogies: An International Journal, 12, 41-57.

Donaldson, G. W., \& Donaldson, L. E. (1958). Outdoor education: a definition. Journal of Health-Physical Education-Recreation, 17,6 3 .

Dror, Y. (2011). Field trips as part of national education. In: G. Cohen \& Eli Shaish (Eds.). The field trips as an educational and value tool (pp. 22-33). Jerusalem: The Ministry of Education (in Hebrew).

Falk, J. H., \& Dierking, L. D. (200o). Learning from museums: visitor experiences and the making of meaning. Walnut Creek, CA: AltaMira Press.

Feinstein, N. W., \& Meshoulam, D. (2014). Science for what public? Addressing equity in American science museums and science centers. Journal of Research in Science Teaching, 51(3), 368-394.

Gertel, G. (2010). The natural path (in Hebrew). Bnei-Brak: Sifriat Poalim Hakibbutz Hameuchad Publishers.

Gutiérrez, K. D., \& Rogoff, B. (2003). Cultural Ways of Learning: Individual Traits or Repertoires of Practice. Educational Researcher, 32(5), 19-25.

Milner, I. (2000). How fun, we almost got killed. In: Benstein, J. (Ed.). A place for thought: Readings in environmental thought. Tel Aviv: The Heschel Sustainability Center (pp. 314-318) (in Hebrew).

Mintz, K., \& Tal, T. (2014). Sustainability in higher education courses: Multiple learning outcomes. Studies in Educational Evaluation, 41, 113-123.

Morag, O., Tal, T., \& Keren-Rotem, T. (2013). Long-term educational programs in nature parks: Characteristics, outcomes and challenges. International Journal of Environmental and Science Education, 8, 427-449.

Myres-JDC-Brookdale (2018). The Arab population of Israel: Facts and numbers. The Myres-JDC-Brookdale Inst. Jerusalem (in Hebrew). 
National Research Council (2009). Learning Science in Informal Environments: People, Places, and Pursuits. Washington, DC: The National Academies Press. https://doi .org/10.17226/1219o.

OECD (nd). Recognition of non-formal and informal learning - Home. Retrieved from: http://www.oecd.org/education/skills-beyond-school/recognitionofnon-formal andinformallearning-home.htm.

Sedawi, W., Ben-Zvi Assaraf, O., \& Cwikel, J. (2014). Conceptualizations of wasterelated implications on health and welfare among elementary school students in the Negev's Bedouin Arab community. Cultural Studies of Science Education, 9(4), 935-976.

Stahl, A. (1993). Educating for change in attitudes toward nature and environment among oriental Jews in Israel. Environment and Behavior, 25, 3-21.

TAEQ (ud). Towns Association for Environment Quality. Retrieved from http://taeq.org.

Tal, T. (2009). Three perspectives of environmental education in Israel: Ideologies, national conflicts and the environmental movement. In D. Zandvliet (Ed.), Diversity in Environmental Education Research (pp. 25-41). Sense publishers.

Tal, T. (2016). From schools to nature: Bridging learning environments in Israel. In: M-H Chiu (Ed.). Science Education Research and Practices in Asia: Challenges and Opportunities (pp. 539-552). Singapore: Springer.

Tal, T. (2012). Out-of-school: learning experiences, teaching and students' learning. In Second international handbook of science education (pp. 1109-1122). Dordrecht: Springer.

Tal, T. \& Alkaher, I. (2010). Collaborative environmental projects in a multicultural society: Working from within separate or mutual landscapes? Cultural Studies of Science Education, 5, 325-349.

Tal \& Dallasheh (2021). Engaging the Hands, Heads and Hearts in a medical simulation informal learning environment. Journal of Research in Science Teaching, doi:10.1002/ tea.21677.

Tal, T., \& Morag, O. (2009). Reflective practice as a means for preparing to teach outdoors in an ecological garden. Journal of Science Teacher Education, 20, 245-262.

The Knesset Research and Information Center. (2016). Museums in the periphery: Children and youth visits and governmental support. Submitted to the Child Rights Committee and the Education Committee of the Knesset. Retrieved from https://fs.knesset.gov.il/globaldocs/MMM/467ea147-7f51-e611-8od7-oo155doac bc2/2_467ea147-7f51-e611-8od7-oo155doacbc2_11_7678.pdf.

Tishler, C., Ben-Zvi Assaraf, O., \& Fried, M. (2020). How Do Visitors from Different Cultural Backgrounds Perceive the Messages Conveyed to Them by Their Local Zoo? Interdisciplinary Journal of Environmental and Science Education, 16(3). 
United Nations General Assembly. (2015). Transforming Our World: The 2030 Agenda for Sustainable Development. Draft resolution referred to the United Nations summit for the adoption of the post-2015 development agenda by the General Assembly at its sixty-ninth session. UN Doc. A/70/L.1 of 18 September 2015. 